Document downloaded from:

http://hdl.handle.net/10251/95466

This paper must be cited as:

Badia, J.; Santonja Blasco, L.; Moriana Torró, R.; Ribes-Greus, A. (2010). Thermal analysis applied to the characterization of degradation in soil of polylactide: II. On the thermal stability and thermal decompositon kinetics. Polymer Degradation and Stability. 95(11):2192-2199. doi:10.1016/j.polymdegradstab.2010.06.002

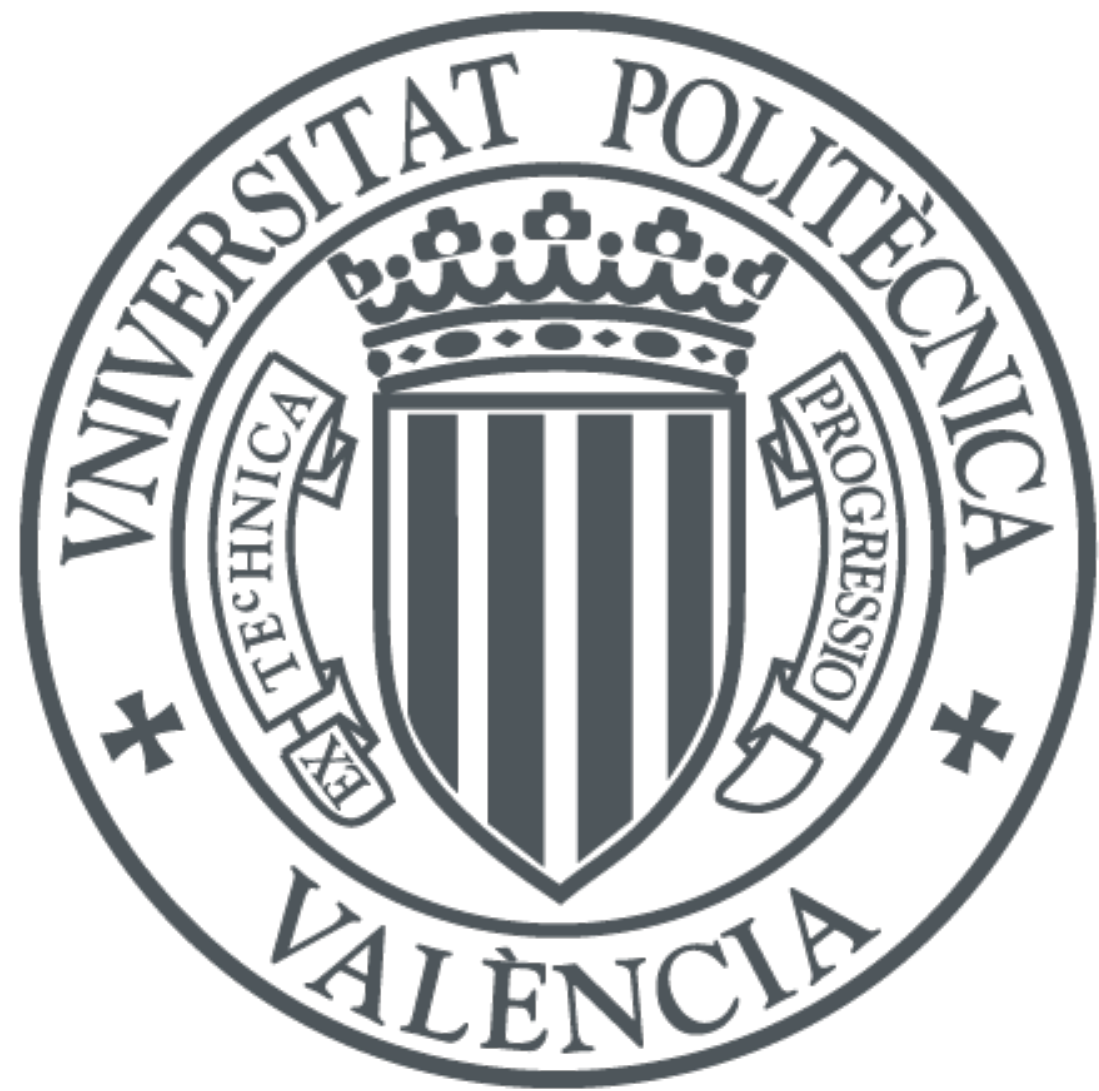

The final publication is available at

http://doi.org/10.1016/j.polymdegradstab.2010.06.002

Copyright Elsevier

Additional Information 
THERMAL ANALYSIS APPLIED TO THE CHARACTERIZATION OF

DEGRADATION IN SOIL OF POLYLACTIDE: II. ON THE THERMAL STABILITY AND THERMAL DECOMPOSITION KINETICS

J.D. Badía, L. Santonja-Blasco, Rosana Moriana, and A. Ribes-Greus*

This is an open-access version, according to http://www.sherpa.ac.uk/romeo/issn/0141-3910/

Full text available at https://www.sciencedirect.com/science/article/pii/S0141391010002387

DOI: https://doi.org/10.1016/j.polymdegradstab.2010.06.002

Please, cite it as:

Badía, J. D., Santonja-Blasco, L., Moriana, R., \& Ribes-Greus, A. (2010). Thermal analysis applied to the characterization of degradation in soil of polylactide: II. On the thermal stability and thermal decomposition kinetics. Polymer degradation and stability, 95(11), 2192-2199.

Instituto de Investigación en Tecnología de Materiales.

Universidad Politécnica de Valencia,

Camino de Vera s/n 46071 Valencia, Spain

*To whom correspondence should be addressed.

Corresponding author. Fax: +34963879817

E-mail address: aribes@ter.upv.es 
Title:

THERMAL ANALYSIS APPLIED TO THE CHARACTERIZATION OF DEGRADATION IN SOIL OF POLYLACTIDE: II. ON THE THERMAL STABILITY AND THERMAL DECOMPOSITION KINETICS

\author{
J.D. Badía, L. Santonja-Blasco, Rosana Moriana, A. Ribes-Greus* \\ Instituto de Tecnología de Materiales. Universidad Politécnica de Valencia. \\ Camino de Vera, s/n, 46071, Valencia (Spain) \\ *Corresponding author: Amparo Ribes Greus (A. Ribes-Greus) \\ e-mail:aribes@ter.upv.es \\ $+0034963879817$
}




\title{
THERMAL ANALYSIS APPLIED TO THE CHARACTERIZATION OF DEGRADATION IN SOIL OF POLYLACTIDE: II. ON THE THERMAL STABILITY AND THERMAL DECOMPOSITION KINETICS
}

\begin{abstract}
The disposal stage of polylactide (PLA) was assessed by burying it in active soil following an international standard. Degradation in soil promotes physical and chemical changes in the polylactide properties. The characterization of the extent of degradation underwent by PLA was carried out by using Thermal Analysis techniques. In this paper, studies on the thermal stability and the thermal decomposition kinetics were performed in order to assess the degradation process of a commercial PLA submitted to an accelerated soil burial test by means of multi-linear-non-isothermal thermogravimetric analyses. Results have been correlated to changes in molecular weight, showing the same evolution as that described by the parameters of thermal stability temperatures and apparent activation energies. The decomposition reactions can be described by two competitive different mechanisms: Nucleation model (A2) and Reaction Contracting Volume model (R3). The changes in the kinetic parameters and kinetic models are in agreement with the calorimetric and dynamic-mechanical-thermal results, presented in the Part I of the study_[1].
\end{abstract}

Keywords: polylactide, degradation in soil; thermal decomposition kinetic analysis, isoconversional methods 


\section{Introduction}

Due to the significant impact of plastic waste on the environment, to find eco-friendly solutions to manage the disposal of synthetic plastics is a key challenge. A promising solution is the use of biodegradable polymers for packaging, as well as many other applications. Due to its good thermal, mechanical and processing properties, economic and environmental advantages [2-12], one of the most potential candidates is polylactide (PLA), which is being currently established at the polymer industry. However, the use of new materials would also imply the generation of a new and huge source of polymeric materials waste in the near future, which should be carefully managed. Therefore, the degradation process involved the disposal stage of PLA must be assessed, with the aim of ensuring the completion of its life cycle.

The necessity of developing and implementing fast, cost-effective and reliable characterization testing procedures has been stated in order to ascertain a deeper knowledge about the ongoing interaction of the polymer with its disposal environment [1]. Thermal Analysis techniques have demonstrated to be very appropriate and reliable methodologies to monitor and control the influence of several degradation phenomena on biodegradable polymers, such as hydrolysis, photo-oxidation, swelling, or degradation in soil [13-14]. Chain cleavage processes induce morphological and mechanical changes, as observed by Differential Scanning Calorimetry and DynamicalMechanical-Thermal-Analysis [1]. These morphological changes may alter the thermal decomposition process of the bulk PLA and thus its characterization would also provide 
a complementary interpretation on the macroscopic effects of degradation in soil on PLA. As discussed in previous studies [16-17], the decomposition of PLA during thermal treatment is mainly caused by intramolecular transesterification reactions leading to cyclic oligomers of lactic acid and lactide. Simultaneously, there is a recombination of the cyclic oligomers with linear polyesters through insertion reactions, whereas molecules with longer chains lengths are favoured. Evolved gases in inert atmosphere also contain acetaldehyde, carbon monoxide, carbon dioxide and methylketene, among others [18].

Due to its applicability in the macroscopic scale, the modeling of the thermal decomposition processes in inert or reactive conditions has been broadly applied by using isoconversional and non-isoconversional methods proposed by different authors with good acceptance because of its versatility in different materials [19-20]. The completion of the kinetic triplet, consisting in kinetic model function $f(\alpha)$, apparent activation energy (Ea), and pre-exponential factor (A) can furnish with the knowledge of the polymer thermal decomposition behaviour, and thus be related to the ongoing degradation stage.

The aim of this work is to test the thermal changes that PLA suffers through degradation in soil by Thermal Analysis. To mimic the environmental conditions at which PLA is subjected in non-controlled disposals, PLA is submitted to a standardized accelerated degradation in soil test. Physical and chemical changes occurred to the polylactide properties, throughout the degradation in soil process are analyzed, making efforts on establishing new insights in studying the degradation in soil process on polymers by other accurate methods alternative and complementary to the chemical analytical techniques. The current paper is focused on the influence of degradation in 
soil on the thermal stability and the thermal decomposition kinetics of PLA. Once assessed the effect of degradation in soil on PLA molecular weight (MW), parameters such as the characteristic thermal stability temperatures $\left(T_{o n}, T_{\text {end }}, T_{p}\right)$ and the components of the kinetic triplet $(\mathrm{f}(\alpha)$, A and Ea) have been correlated to MW evolution and consequently evaluated as indicators of degradation.

\section{Theoretical background}

The primary purpose of the kinetic analysis is to obtain the aforementioned kinetic triplet. Recently, Khawan and Flanagan [21-22] have reviewed the relationship between the theoretical decomposition mechanisms and their mathematical models, the so-called kinetic functions $f(\alpha)$. A list of the most common $f(\alpha)$ applied to polymers is given at Table 1.

Table 1

Macroscopic kinetics are complex since they might give information about multiple steps simultaneously occurring, and therefore induce to misleading results [23]. Some investigations have been hence carried out in order to focus on the challenge of clarifying the interpretation of macroscopic kinetics; and have settled isoconversional methods as suitable analysis procedures to evaluate the apparent activation energy (Ea) [23-24]. These methods, which require experiments at several linear heating rates, are based on the assumption that at a constant extent of conversion $\alpha$, the decomposition rate $\mathrm{d} \alpha / \mathrm{dt}$ is a function only of the temperature, and do not need any conversion model assumption at the initial stages of the analysis. The most broadly used isoconversional methods are those developed by Friedman [25] and Flynn-Wall-Ozawa [26, 27] 
(supported on Doyle's integral approximation [28]). These methods give rise to linear functions from which slopes the Ea at a constant $\alpha$ is obtained. Likewise, the model free kinetic method established by Kissinger [29] is widely employed by many authors in order to check their results. This method calculates the activation energy from the slope of a linear function which takes into account the relationship between the peak temperature of the first-derivative thermogravimetric curve and the heating rate employed in the experiment.

Regarding the kinetic function $f(\alpha)$ evaluation, the most common methodologies are those proposed by Criado [30], which allows the comparison of the experimental data to theoretical reduced master-curves, and Coats-Redfern [31], which gives a linear fitting for a given kinetic model function. By combining both methods, Coats-Redfern method is applied to those theoretical kinetic functions $\mathrm{f}-(\alpha)$ that better fit the experimental behaviour according to the results drawn from the Criado method. A comparison of the apparent activation energy Ea obtained from the slope for each $\mathrm{f}(\alpha)$ with the average apparent activation energy given by the Friedman, Flynn-Wall-Ozawa and Kissinger methods $\mathrm{Ea}_{\text {iso }}$ will be deciding in the selection of the $\mathrm{f}(\alpha)$. The preexponential (A) is also obtained from this method, and the kinetic triplet is thus achieved, which is automatically related to the physical decomposition mechanism. An extended explanation of these methods can be found elsewhere [32]. To summarize, Figure 1 schematically represents the theoretical description of these methods and the kinetic strategy followed at this paper.

Figure 1 


\section{Experimental procedures}

\subsection{Material and sample preparation}

A commercial polylactide with $3.8 \%$ content of meso-lactide, obtained from renewable resources by ring opening polymerization supplied by Natureworks (Minnetonka, USA) was used in this study. This PLA is a commercial resin with a number-average molecular weight of $102.130 \mathrm{~g} / \mathrm{mol}$, as measured by Gel Permeation Chromatography.

Pellets of PLA were dried with demoisturized air at $80^{\circ} \mathrm{C}$ during 4 hours. Rectangular bars were prepared by compression moulding in a Collin PCS-GA Type Press 800 (GA, USA) at an initial temperature of the hot plates of $195^{\circ} \mathrm{C}$ and final temperature of $60^{\circ} \mathrm{C}$. Five pressure steps were performed as follows: 5 minutes at 6 bar, 8 minutes at 75 bar, 8 minutes at 155 bar, 4 minutes at 215 bar, and 11 minutes at 45 bar. Test specimens were presented as bars of ( $145 \times 10 \times 2 \mathrm{~mm})$. Since this work approaches the degradation in soil of discarded consumer goods, which are obtained by means of, at least, one processing step, "non-buried PLA" has been considered the starting material of the study.

\subsection{Accelerated soil burial test}

PLA plates were subjected to a controlled degradation in soil test under controlled conditions (temperature, water content and $\mathrm{pH}$ ), following the ISO 846-1997 International Norm [33], according to method D. Samples were buried in biologically active soil and kept in a Heraeus B12 (Hanau, Germany) culture oven at $28^{\circ} \mathrm{C}$. The soil 
used in these tests was a red soil extract taken from a culture field in Alginet (Valencia). To ensure the oxygenation of the soil, a protocol of periodical air oxygen supply was followed. Microbial activity of soil was monitored with cotton along the extension of the experiment. According to norm, if the activity of the cellulose-degrading microorganisms is in order, the case is also applicable to the rest of flora. The soil was maintained at approximately $\mathrm{pH} 7$ and a relative humidity of $0.87 \mathrm{~g}$ water/g wet soil. Test specimens were extracted at 30, 150, 300 and 450 days, cleaned and kept in a desiccator during 4 days in order to ensure water desorption before being analyzed.

\subsection{Thermogravimetric analysis}

Experiments were carried out in a Mettler-Toledo TGA/SDTA 851 (Columbus, OH), from 25 to $750^{\circ} \mathrm{C}$ at different heating rates $\left(\beta=5,10,15,20,25,30{ }^{\circ} \mathrm{C} / \mathrm{min}\right)$, under constant flow of $50 \mathrm{~mL} / \mathrm{min}$ of Argon atmosphere. 


\section{Results and discussion}

The influence of degradation in soil on polylactide has been deeply characterized by Thermogravimetry (TGA). The changes in the thermal stability have been firstly studied. A further assessment of the thermal decomposition behaviour in the bulk PLA is performed. Results are related to those showed by Differential Scanning Calorimetry (DSC) and Dynamical Mechanical Thermal Analysis (DMTA), reported in the Part I of the study [1]. Discussion is given in terms of both the effects of degradation in soil on the physical-chemical properties of PLA, and the reliability of these thermal analysis techniques to offer reliable indicators of the degradation extent.

\subsection{Thermal stability}

A preliminary analysis of the differences observed in thermal stability temperatures for non-buried PLA and samples submitted to the accelerated soil burial test was performed. For this purpose, the thermal decomposition (TG) curves and their firstorder derivative (DTG) curves for samples extracted at 30, 150, 300 and 450 of burying have been analysed at different heating rates and compared to the TG and DTG curves of the non-buried PLA. Figure 2 shows the influence of the degradation process on the TG and DTG curves in terms of the conversion degree evolution displayed for nonburied and 450-days-buried PLA samples; the other soil burial experiments were omitted for the sake of clarity.

Figure 2 
As usual, higher heating rates $(\beta)$ lead to shift the thermograms to higher temperatures. PLA thermal decomposition occurs through a single decay stage, regardless the degradation in soil time and the $\beta$ employed for the thermogravimetric analysis. The mass loss was around $98-99 \%$ in all cases. The corresponding decomposition onset and endset temperatures $\left(\mathrm{T}_{\mathrm{on}}, \mathrm{T}_{\text {end }}\right)$ were obtained by a tangential intercept method onto the TG curve. Likewise, the peak temperature of the DTG curve, which is related to the inflection temperature of the $\mathrm{TG}$ curve $\left(\mathrm{T}_{\mathrm{P}}\right)$ was also considered. Figure 3 displays the $\mathrm{T}_{\mathrm{on}}, \mathrm{T}_{\mathrm{end}}$ and $\mathrm{T}_{\mathrm{P}}$ evolution along the degradation in soil process at the experiment of lower $\beta\left(5^{\circ} \mathrm{C} \cdot \min ^{-1}\right)$, since it is supposed to offer the best accuracy and the major independence with the experimental TGA conditions [23]. All thermal stability temperatures describe the same behaviour, clearly differenced in two stages: firstly, an overall increase of around $5{ }^{\circ} \mathrm{C}$ is stated; afterwards, the decomposition temperatures continuously diminish, describing an attenuated decreasing tendency. These results suggest modifications in the arrangement of chains in the bulk PLA matrix. Initial hydrolytic reactions might give out smaller free chains able to react or reorganize, thus offering a slightly higher resistance to the thermal decomposition [34]. Later on, the degradation weakens the structure of the bulk polymer, and thus lower temperatures are capable of overcoming its thermal stability. The results from thermogravimetric analysis lead to guess that degradation in soil produces small changes in the bulk polymer, since the interaction of the polymer and the testing environment takes place slowly, as it has been shown in other studies [13-14]. However, these small variations might indicate modifications in the thermal decomposition kinetic model. Further analysis is therefore carried out to establish good indicators which correlate the thermal decomposition behaviour of PLA with its degradation in soil stage. 
Figure 3

\subsection{Thermal decomposition kinetic model}

In the attempt to develop a model for plastic thermal behaviour in full scale systems, the main purpose is to describe the thermal decomposition of polymers in terms of an intrinsic kinetics, in which heat and mass transfer limitations are not included. Generally kinetic models are proposed in literature for plastics and biomasses. These models do not take into account the rigorous and exhaustive description of the chemistry of thermal decomposition of polymers and describe the process by means of a simplified reaction pathway. Each single reaction step considered is representative of a complex network of reactions [21]. The obtaining of the aforementioned kinetic triplet may provide new knowledge regarding the kinetic model of PLA thermal decomposition. A deep kinetic analysis according to the kinetic methodology formerly proposed in Figure 1 has been performed. The Friedman, Flynn-Wall-Ozawa and Kissinger methods have been initially applied to evaluate the degradation in soil effect on the apparent activation energy (Ea) of the PLA thermal decomposition. These three methods offer good experimental data fittings to straight lines, for all degradation in soil times studied. Figure $4(a, b, c)$ shows the application of these methods to the nonburied PLA.

Figure 4

The Ea for every constant conversion degree $\alpha$ value has been obtained from the slope of each line. Since the main mass loss decomposition process occurs in the $\alpha$ domain comprised between 0.2 and 0.7 for all samples, the analyses have been focused in that 
range. Table 2 shows the isoconversional apparent activation energy $\mathrm{Ea}_{\alpha}$ values for all samples submitted to the soil burial test. In order to investigate the degradation consequences on the PLA thermal decomposition kinetics, the average apparent activation energy $\mathrm{Ea}_{\mathrm{iso}}$ value has been taken. Figure 5 represents the $\mathrm{Ea}_{\mathrm{iso}}$ evolution with the soil burial time for the three employed methods. As can be seen, a consistent behaviour in a small confidence range has been given by all of them. The $\mathrm{Ea}_{\text {iso }}$ tendency is similar to the evolution described by all the characteristic thermal stability temperatures and molecular weights [1]. In a first stage, a slight increase in molecular weight $\left(\mathrm{Mn}=1.02 \cdot 10^{5} \mathrm{~g} \cdot \mathrm{mol}^{-1}\right.$ at 0 days and $1.08 \cdot 10^{5} \mathrm{~g} \cdot \mathrm{mol}^{-1}$ at 30 days $)$ strengthens the suggestion previously drawn on molecular recombinations of smaller chains into the polymeric backbone for the action of the humidity of the soil [34], which is further supported by the increase of the $\mathrm{Ea}_{\mathrm{iso}}$, since more energy is needed to trigger the thermal decomposition. Later on, the $\mathrm{Ea}_{\mathrm{iso}}$ continuously decreases, which indicates a progressive weakening of the PLA structure, related to a continuous decrease in molecular weight $\left(\mathrm{Mn}=9.1 \cdot 10^{4} \mathrm{~g} \cdot \mathrm{mol}^{-1}\right.$ at 150 days, $7.6 \cdot 10^{4} \mathrm{~g} \cdot \mathrm{mol}^{-1}$ at 300 days, and $5 \cdot 10^{4} \mathrm{~g} \cdot \mathrm{mol}^{-1}$ at 450 days) as a consequence of the degradation in soil subjected, as it was shown [1]. These changes support the hypothesis previously drawn, which considered modifications on the thermal decomposition mechanism as a degradation in soil effect, as it is shown as follows.

Table 2.

Figure 5.

Concerning the completion of the kinetic triplet, the kinetic model function $f(\alpha)$, and the pre-exponential factor (A) should be obtained. Criado method has been applied for 
all the theoretical $f(\alpha)$ related at Table 1. Figure 4 (d) shows the comparison of the reduced Criado functions of non-buried PLA to the master-curves for the experiments carried out at the slower heating rate $\left(5^{\circ} \mathrm{C} \cdot \mathrm{min}^{-1}\right)$, which are supposed to offer more accurate results [23]. This method allows for the discrimination of the most possible kinetic models which can explain the thermal decomposition behaviour of polymers. Nevertheless, a parallel evaluation of the apparent activation energies Ea is required to verify the chosen kinetic function $f(\alpha)$. Among the different methods that calculate the Ea from a given $f(\alpha)$, Coats-Redfern method has been demonstrated to offer the most precise results [35]. In that way, the results of the combination of the analyses performed by means of the application of Criado, Coats-Redfern and the isoconversional methods are shown at Table 3, together with the kinetic triplet obtained and the corresponding physical thermal decomposition model for each soil burial time. The knowledge of the complete kinetic triplet allows mathematically describing the thermal degradation process at any time of the soil burial experiment. As can be seen at Figure 6, the theoretical kinetic model drawn from the analysis to all samples perfectly fit to the thermogravimetric experimental data.

Table 3

Figure 6

The kinetic analysis methodology has permitted to accurately model the thermal decomposition process along the degradation in soil test. The kinetic triplet interpretation eases the complexity of the decomposition processes taking place, and permits to relate the changes induced by degradation in soil to the changes in the morphology of the bulk PLA. The non-buried PLA thermal decomposition mechanism 
is described by a Nucleation model (A2). This kind of kinetic model is quite common in crystallization processes, but have only been observed in few studies dealing with thermal decomposition processes of polymers [36-42]. In these studies, the controversy of the relationship between the mathematical models and the physical mechanisms is patent. Even being aware of the limitations of these studies, a physical approach of the influence of degradation in soil on the bulk PLA have been drawn from our kinetic analysis. Therefore, the A2 model indicates the presence of active zones (nuclei), more chemically liable to thermal decomposition [34], which activate the formation and growth of gas bubbles in the polymer melt [42]. However, the degradation in soil process alters the thermal decomposition behaviour of PLA. When PLA samples are submitted to the accelerated soil burial test, changes in the kinetic triplet are involved, due to the humidity and the presence of micro-organisms, which mainly induce chemical changes in the polymeric structure [45-48]. In this first stage, humidity may affect the PLA structure and the effect of ingestion and coalescence nuclei processes could difficult the molecules release and produce a change in the thermal decomposition mechanism, which may be primarily controlled by a Reaction Contracting model (R3). This model explains the thermal decomposition in a generalized fashion throughout the bulk PLA, where the gas release is controlled in the phase boundaries. After this first stage, the thermal decomposition mechanism remains being described by a R3 model but, due to the continuous interaction between the polymer and the degrading environment, low molecular weight compounds might be released. Hence, the characteristic temperatures and the $\mathrm{Ea}_{\mathrm{iso}}$ of the thermal decomposition process show a decrease, which is a sign of the progressive weakening of PLA structure, since it requires lower energy to activate its thermal decomposition process as longer is PLA submitted to degradation in soil. The R3 kinetic model is maintained during almost 300 
days but after this time, in agreement with the morphological variations stated by the DSC and DMTA results [1], a rearrangement of chains into weaker conformations is produced and the generalized decomposition may be therefore disabled, giving relevance to the decomposition in specific sites (nuclei) and thus the thermal decomposition process is again governed by an A2 Nucleation model.

\section{Conclusions}

Commercial polylactide was buried in active soil in order to mimic its disposal stage following an international standard, and the changes in their physical and chemical properties were assessed by Thermal Analysis techniques. The research in this second paper focuses on the thermal stability and thermal decomposition kinetics of PLA. Multi-rate linear-non-isothermal thermogravimetric experiments have been performed and indicators for monitoring the influence of degradation in soil on the bulk PLA have been proposed.

A single thermal decomposition stage has been stated for all degraded-in-soil PLA samples, regardless the burial time and the heating rate employed. The effect of degradation in soil on PLA thermal stability has been evaluated in terms of the onset, endset and the peak decomposition temperatures. All temperature indicators follow the same double-stage behaviour: a first increase related to the major degrading activity in the polymer; and a continuous attenuated decay along the degradation in soil process. These changes have been also assessed by the evolution of the apparent activation energy, being in that case the difference between both stages more noticeable. The correlation of these parameters to the evolution observed for the molecular weight 
evolution strengthens the usefulness of thermogravimetry as a means for monitoring the influence of degradation on polymers.

A kinetic analysis methodology, consisting in the combination of five different methods (namely Friedman, Flynn-Wall-Ozawa, Kissinger, Criado and Coats-Redfern) has been successfully applied and has allowed the determination of the PLA kinetic triplet evolution throughout the degradation in soil process. The PLA thermal decomposition mechanism is influenced, since it can be described by two competitive different decomposition models: on the one hand, a Nucleation model (A2), which gives importance to specific decomposition sites; and on the other hand, a Reaction Contracting model (R3), which represents a particles release generalized on the whole polymer surface. Therefore, the knowledge of the thermal decomposition model at each degradation stage has permitted to interpret from a macroscopic point of view the degradation in soil consequences on PLA bulk morphology.

\section{Acknowledgements}

The authors would like to acknowledge the Ministerio de Educación y Ciencia (Spanish Government) and the European Regional Development Fund for the economical support through the Project ENE2007/67584/C03-02 and the research position granted through the FPU pre-doctoral program to J.D. Badía. The Ministerio of Ciencia e Innovación is acknowledged by L.Santonja-Blasco and Rosana Moriana for the research position by means of the FPI pre-doctoral programme. 


\section{REFERENCES}

1. Santonja-Blasco L., Rosana Moriana, Badía J.D., Ribes-Greus A. Thermal analysis applied to the characterization of degradation in soil of polylactide: I. Calorimetric and viscoelastic analyses. Manuscript. Submitted to Polymer Degradation and Stability.

2. Tsuji H; Doi Y, Steinbückel A editors. Biopolymers. Polyesters III. Applications and Commercial Products. Wiley-VCH Verlag GmbH, Weinheim, 2002

3. Auras R, Harte B, Selke S. An overview of polylactides as packaging materials. Macromolecular Bioscience 2004; 4: 835-864.

4. Gupta A P, Kumar V. New emerging trends in synthetic biodegradable polymersPolylactide: a critique. European Polymer Journal 2007; 43(10): 4053-4074.

5. Holland S J, Tighe B J. Biodegradable Polymers in Advances in Pharmaceutical Sciences. London: Academic Press London, 1992.

6. Bogaert J C, Coszach P.Poly(lactic acids): a potential solution to plastic waste dilemma. Macromolecular Symposia 2000; 153: 287.

7. Dorgan J R, Lehermeier H J, Palade L I, Cicero J. Thermal and rheological properties of commercial-grade poly (lactic acid) s. Macromolecular Symposia 2001; 175: 55. 
8. Tsuji H, Ikada Y. Crystallization from the melt of poly (lactide) s with different optical purities and their blends. Macromolecular Chemistry and Physics 1996; 197: 3483.

9. Sarasua J R, Prud'homme R E, Wisniewski M, Le Borgne A, Spassky N. Crystallization and melting behavior of polylactides Macromolecules 1998; 31: 3895.

10. Miyata T, Masuko T. Crystallization behaviour of poly (L-lactide) Polymer, 1998. 39: 5515 .

11. Dattaa R, Tsaia S P, Bonsignorea P, Moona S H, Frank J R. Technological and economical potential of poly(lactic acid) and lactic acid derivatives. FEMS Microbiol. Rev 1995; 16: 221.

12. Vink E T H, Rabago K R, Glassner D A, Gruber P R. Applications of life cycle assessment to Nature Works polylactide (PLA) production. Polymer Degradation and Stability 2003; 80(3): 403-419.

13. Santonja-Blasco L, Contat-Rodrigo L, Moriana-Torró R, Ribes-Greus A. Thermal characterization of polyethylene blends with a biodegradable masterbatch subjected to thermo-oxidative treatment and subsequent soil burial test. Journal of Applied Polymer Science 2007; 106: 2218-2230. 
14. Moriana-Torró R, Contat-Rodrigo L, Santonja-Blasco L, Ribes-Greus A. Thermal characterisation of photo-oxidized HDPE/Mater-Bi and LDPE/Mater-Bi blends buried in soil. Journal of Applied Polymer Science 2008; 109: 1177-1188.

15. Torres A, Li SM, Roussos S, Vert M. Poly(lactic acid) degradation in soil or under controlled conditions. Journal of Applied Polymer Science 1998; 62 (13): 2295 - 2302

16. Hakkarainen M. Aliphatic polyesters: abiotic and biotic degradation and degradation products. Adv Polym Sci 2002;157:113-38.

17. Ho KGL, Pometto AL, Hinz PN. Effects of temperature and relative humidity on polylactic acid plastic degradation. J. Environ Polym Degrad 1999;7: 83-92.

18. Mc Neill I. C., Leiper H. A. Degradation studies of some polyesters and polycarbonates. II: Polylactide: degradation under isothermal conditions, thermal degradation mechanism and photolysis of the polymer. Polymer Degradation and Stability. 1985, 11(4): 309-326.

19. Ramis X C, Salla J M, Morancho J M, Vallés A, Contat L, Ribes A. Thermal degradation of polypropylene/starch-based materials with enhanced biodegradability. Polymer Degradation and Stability 2004; 86: 483-491.

20. Alvarez V A, Vázquez A. Thermal degradation of cellulose derivatives/starch blends and sisal fibre biocomposites. Polymer Degradation and Stability 2004; 84: 1321. 
21. Wunderlich B.Thermal analysis of Polymeric Materials. Berlin, ed. Springer. 2005.

22. Khawam A, Flanagan D R. Solid-state kinetic models: Basics and mathematical fundamentals. Journal of Physical Chemistry part B 2006; 110: 17315-17328.

23. Brown M.,editor. Introduction to Thermal Analysis. 2nd Edition. Techniques and Applications. Secaucus, NJ, USA: Kluwer Academic Publishers, 2001.

24. Brown M E, Vyazovkin S, Nomen R, Sempere J, Burnham A, Opfermann J, Strey R, Anderson H L, Kemmler A, Keuleers R, Janssens J, Desseyn H O, Li C R, Tang T B, Roduit B, Malek J, Mitsuhashi T. Computational aspects of kinetic analysis._Part A: The ICTAC kinetics project-data, methods and results. Thermochimica Acta 2000; 355: 125-143.

25. H.L. Friedman, Kinetics and gaseous products of thermal decomposition of polymers, J Macromol Sci Part A 1967 1 (1): 57-79

26. Flynn J H, Wall L A. A quick, direct method for the determination of activation energy from thermogravimetric data. Journal of Polymer Science 1966; 4: 323-342.

27. Ozawa, T. Kinetic analysis of derivative curves in thermal analysis. Journal of Thermal Analysis 1970; 2: 301. 
28. Doyle C D. Series approximations to the equation of thermogravimetric data. Nature 1965; 207: 290.

29. Kissinger HE. Reaction kinetics in differential thermal analysis. Analytical Chemistry 1957; 29(11): 1702-1706.

30. Criado J M. Kinetic analysis of DTG data from master curves. Thermochimica Acta $1978 ; 24: 186-189$.

31. Coats, Redfern. Kinetic parameters from thermogravimetric data. Nature 1964; 68(201): 4914.

32. Rosana Moriana, Badia J.D., Santonja-Blasco L., Ribes-Greus A. Assessing the mechanical enhancement and the thermostabilising effect of adding cotton fibres to a starch-based matrix using thermal analysis. Manuscript in preparation.

33. ISO 846, 1997. Plastics-determination of behaviour under the action of microoganisms. Evaluation by visual examination or measurement of changes in mass or physical properties.

34. Liua X. , Zoub Y., Lia W., Caoa G., Chen W. Kinetics of thermo-oxidative and thermal degradation of poly(d,1-lactide) (PDLLA) at processing temperature. Polymer Degradation and Stability 2006; 91(12): 3259-3265. 
35. Pérez-Maqueda L. A., Sánchez-Jiménez P. E. , J. M. Criado. Kinetic analysis of solid-state reactions: Precision of the activation energy calculated by integral methods. Inc. Int J Chem Kinet 2005; 37: 658-666.

36. Stoeva St., Gjurova K., Zagorcheva M., Thermal analysis study on the degradation of the solid-state chlorinated poly (ethylene). Polymer Degradation and Stability 2000; $67,117-128$

37. Li L., Guan C., Zhang, A., Chen D., Qing, Z. Thermal stabilities and the thermal degradation kinetics of polyimides. Polymer Degradation and Stability 2004; 84, 369373

38. Sun J.T., Huang Y.D., Gong G.F., Cao H.L. Thermal degradation kinetics of poly(methylphenylsiloxane) containing methacryloyl groups. Polymer Degradation and Stability 2005; 91, 339-346

39. Meng X., Huang,Y., Yu, H., Lu, M., Thermal degradation kinetics of polyimide containing 2,6-benzobisoxazole units. Polymer Degradation and Stability 2007; 92, 962-967

40. Chen Y., Wang, Q., Thermal oxidative degradation kinetics of flame-retarded polypropylene with intumescent flame-retardant master batches in situ prepared in twinscrew extruder. Polymer Degradation and Stability 2007; 92, 280-291 
41. Budrugeac P., Segal E., Pérez-Maqueda L. A., Criado J. M., The use of the IKP method for evaluating the kinetic parameters and the conversion function of the thermal dehydrochlorination of PVC from non-isothermal data. Polymer Degradation and Stability 2004; 84(2), 311-320

42. Grausea G., Ishibashia J., Kamedaa T., Bhaskarb T., Yoshioka T., Kinetic studies of the decomposition of flame retardant containing high-impact polystyrene. Polymer Degradation and Stability 2010, doi: 10.1016/j.polymdegradstab.2010.02.008

45. Proikakis C.S., Mamouzelos N. J., Tarantili P.A., Andreopoulos A. G., Swelling and hydrolytic degradation of poly(D,L-lactic acid) in aqueous solutions. Polymer Degradation and Stability 2006; 91 (3): 614-619

46. Zhang X, Wyss U P, Pichora D, Goosen M F A. An investigation of poly (lactic acid) degradation. Journal of Bioactive and Compatible Polymers 1994; 9: 80.

47. Gupta A P, Deshmukh V G. Thermal Oxidative Degradation of Poly-lactic Acid;Part I: Activation Energy of Thermal Degradation in Air. Colloid and Polymer Science 1982; 260: 11.

48. Kopinke F D, Remmler M, Mackenzie K, Möder M, Wachsen O. Thermal decomposition of biodegradable polyesters-II. Poly(lactic acid). Polymer Degradation and Stability 1996; 53(3): 329-342. 


\section{THERMAL ANALYSIS APPLIED TO THE CHARACTERIZATION OF \\ DEGRADATION IN SOIL OF POLYLACTIDE: II. ON THE THERMAL STABILITY AND THERMAL DECOMPOSITION KINETICS}

J-D. Badía, L. Santonja-Blasco, R. Moriana, A. Ribes-Greus*

\section{CAPTIONS TO FIGURES}

Figure 1. Methodology applied for the characterisation of the thermal decomposition kinetics of PLA submitted to degradation in soil.

Figure 2. Comparison of the conversion degree evolution and its first-derivative thermogravimetric curve plot for non-degraded PLA and PLA buried during 450 days.

Figure 3. Effect of degradation in soil on the thermal stability temperatures obtained from TGA experiments at $5{ }^{\circ} \mathrm{C} / \mathrm{min}$.

Figure 4. Kinetic methods applied to non-degraded PLA. a) Friedman method; b) Flynn-Wal-Ozawa method. c) Kissinger method. Insert: Determination of the peak decomposition temperature. d) Criado method.

Figure 5. Evolution of the apparent activation energy throughout the degradation in soil process.

Figure 6. Comparison of experimental TG curves (symbols) to fitted kinetic functions (solid lines) obtained from the kinetic methodology. 


\section{THERMAL ANALYSIS APPLIED TO THE CHARACTERIZATION OF \\ DEGRADATION IN SOIL OF POLYLACTIDE: II. ON THE THERMAL STABILITY AND THERMAL DECOMPOSITION KINETICS}

J-D. Badía, L. Santonja-Blasco, R. Moriana, A. Ribes-Greus*

\section{CAPTIONS TO TABLES}

Table 1. List of common kinetic functions to explain the thermal decomposition mechanisms in bulk polymers.

Table 2. Apparent activation energies values obtained by the Friedman $\left(\mathrm{Ea}_{\mathrm{F}}\right)$, FlynnWall-Ozawa $\left(\mathrm{Ea}_{\mathrm{FwO}}\right)$ and Kissinger $\left(\mathrm{Ea}_{\mathrm{K}}\right)$ methods.

Table 3. Results of kinetic methodology. Evolution of kinetic triplet of PLA thermal decomposition throughout the degradation in soil process. 
Table 1

J-D. Badía, L. Santonja-Blasco, R. Moriana, A. Ribes-Greus

\begin{tabular}{|c|c|c|}
\hline model & $\begin{array}{c}\text { differential form } \\
\mathbf{f}(\alpha)=1 / \mathbf{k} \cdot \mathbf{d} \alpha / \mathbf{d t}\end{array}$ & $\begin{array}{c}\text { integral form } \\
\mathbf{g}(\alpha)=\mathbf{k} \cdot \mathbf{t}\end{array}$ \\
\hline \multicolumn{3}{|c|}{ NUCLEATION MODELS } \\
\hline Avrami-Erofeyev (A2) & $2 \cdot(1-\alpha) \cdot[-\ln (1-\alpha)]^{1 / 2}$ & {$[-\ln (1-\alpha)]^{1 / 2}$} \\
\hline Avrami-Erofeyev (A3) & $3 \cdot(1-\alpha) \cdot[-\ln (1-\alpha)]^{2 / 3}$ & {$[-\ln (1-\alpha)]^{1 / 3}$} \\
\hline Avrami-Erofeyev (A4) & $4 \cdot(1-\alpha) \cdot[-\ln (1-\alpha)]^{3 / 4}$ & {$[-\ln (1-\alpha)]^{1 / 4}$} \\
\hline \multicolumn{2}{|c|}{ GEOMETRICAL CONTRACTION MODELS } \\
\hline Contracting area (R2) & $2 \cdot(1-\alpha)^{1 / 2}$ & $1-(1-\alpha)^{1 / 2}$ \\
\hline Contracting volume (R3) & $3 \cdot(1-\alpha)^{1 / 3}$ & $1-(1-\alpha)^{1 / 3}$ \\
\hline \multicolumn{2}{|c|}{ REACTION-ORDER MODELS } & -1 - $1(1-\alpha)$ \\
\hline Zero-order (F0/R1/n=0) & $(1-\alpha)$ & $\frac{1}{1-\alpha}-1$ \\
\hline First-order (F1,n=1) & $(1-\alpha)^{2}$ & $1 / 2 \cdot\left[\frac{1}{(1-\alpha)^{2}}-1\right]$ \\
\hline Second-order (F2,n=2) & $(1-\alpha)^{3}$ &
\end{tabular}




\section{TABLE 2}

J-D. Badía, L. Santonja-Blasco, R. Moriana, A. Ribes-Greus

\begin{tabular}{|c|c|c|c|c|c|c|c|c|c|c|c|c|c|c|c|}
\hline & & PLA_0days & & & PLA_30day & & & LA_150day & & & LA_300da & & & LA_450day & \\
\hline$\alpha$ & $\begin{array}{c}\mathrm{Ea}_{\mathrm{F}} \\
\left(\mathrm{kJ} \cdot \mathrm{mol}^{-1}\right) \\
\end{array}$ & $\begin{array}{c}\begin{array}{c}\mathrm{Ea} \\
\mathrm{FWO} \\
\left(\mathrm{kJ} \cdot \mathrm{mol}^{-1}\right)\end{array} \\
\end{array}$ & $\begin{array}{c}\mathrm{Ea}_{\mathrm{K}} \\
\left(\mathrm{kJ} \cdot \mathrm{mol}^{-1}\right) \\
\end{array}$ & $\begin{array}{c}\mathrm{Ea}_{\mathrm{F}} \\
\left(\mathrm{kJ} \cdot \mathrm{mol}^{-1}\right)\end{array}$ & $\begin{array}{c}\begin{array}{c}\mathrm{Ea}_{\mathrm{FWO}} \\
\left(\mathrm{kJ} \cdot \mathrm{mol}^{-1}\right)\end{array} \\
\end{array}$ & $\begin{array}{c}\mathrm{Ea}_{\mathrm{K}} \\
\left(\mathrm{kJ} \cdot \mathrm{mol}^{-1}\right) \\
\end{array}$ & $\begin{array}{c}\mathrm{Ea}_{\mathrm{F}} \\
\left(\mathrm{kJ} \cdot \mathrm{mol}^{-1}\right)\end{array}$ & $\begin{array}{c}\mathrm{Ea}_{\mathrm{FWO}} \\
\left(\mathrm{kJ} \cdot \mathrm{mol}^{-1}\right)\end{array}$ & $\begin{array}{c}\mathrm{Ea}_{\mathrm{K}} \\
\left(\mathrm{kJ} \cdot \mathrm{mol}^{-1}\right) \\
\end{array}$ & $\begin{array}{c}\mathrm{Ea}_{\mathrm{F}} \\
\left(\mathrm{kJ} \cdot \mathrm{mol}^{-1}\right)\end{array}$ & $\begin{array}{c}\mathrm{Ea}_{\mathrm{FWO}} \\
\left(\mathrm{kJ} \cdot \mathrm{mol}^{-1}\right)\end{array}$ & $\begin{array}{c}\mathrm{Ea}_{\mathrm{K}} \\
\left(\mathrm{kJ} \cdot \mathrm{mol}^{-1}\right) \\
\end{array}$ & $\begin{array}{c}\mathrm{Ea}_{\mathrm{F}} \\
\left(\mathrm{kJ} \cdot \mathrm{mol}^{-1}\right)\end{array}$ & $\begin{array}{c}\mathrm{Ea}_{\mathrm{FWO}} \\
\left(\mathrm{kJ} \cdot \mathrm{mol}^{-1}\right)\end{array}$ & $\begin{array}{r}\mathrm{Ea}_{\mathrm{K}} \\
\left(\mathrm{kJ} \cdot \mathrm{mol}^{-1}\right)\end{array}$ \\
\hline 0.2 & 205.5 & 206.0 & \multirow{6}{*}{206.7} & 235.7 & 260.9 & \multirow{6}{*}{259.7} & 217.7 & 233.0 & \multirow{6}{*}{239.0} & 180.5 & 215.3 & \multirow{6}{*}{214.3} & 195.2 & 222.6 & \multirow{6}{*}{199.7} \\
\hline 0.3 & 207.6 & 212.4 & & 259.8 & 261.3 & & 224.3 & 241.7 & & 201.7 & 218.8 & & 199.2 & 214.3 & \\
\hline 0.4 & 208.0 & 202.5 & & 271.8 & 265.9 & & 229.1 & 238.9 & & 211.7 & 217.2 & & 201.7 & 203.3 & \\
\hline 0.5 & 206.1 & 202.7 & & 283.9 & 272.0 & & 231.6 & 237.4 & & 219.8 & 207.1 & & 199.3 & 193.2 & \\
\hline 0.6 & 205.4 & 197.0 & & 274.8 & 263.9 & & 233.9 & 240.3 & & 222.5 & 202.5 & & 194.8 & 179.7 & \\
\hline 0.7 & 204.1 & 191.8 & & 252.7 & 261.7 & & 235.7 & 235.7 & & 222.9 & 186.0 & & 193.6 & 176.4 & \\
\hline
\end{tabular}


TABLE 3

J-D. Badía, L. Santonja-Blasco, R. Moriana, A. Ribes-Greus

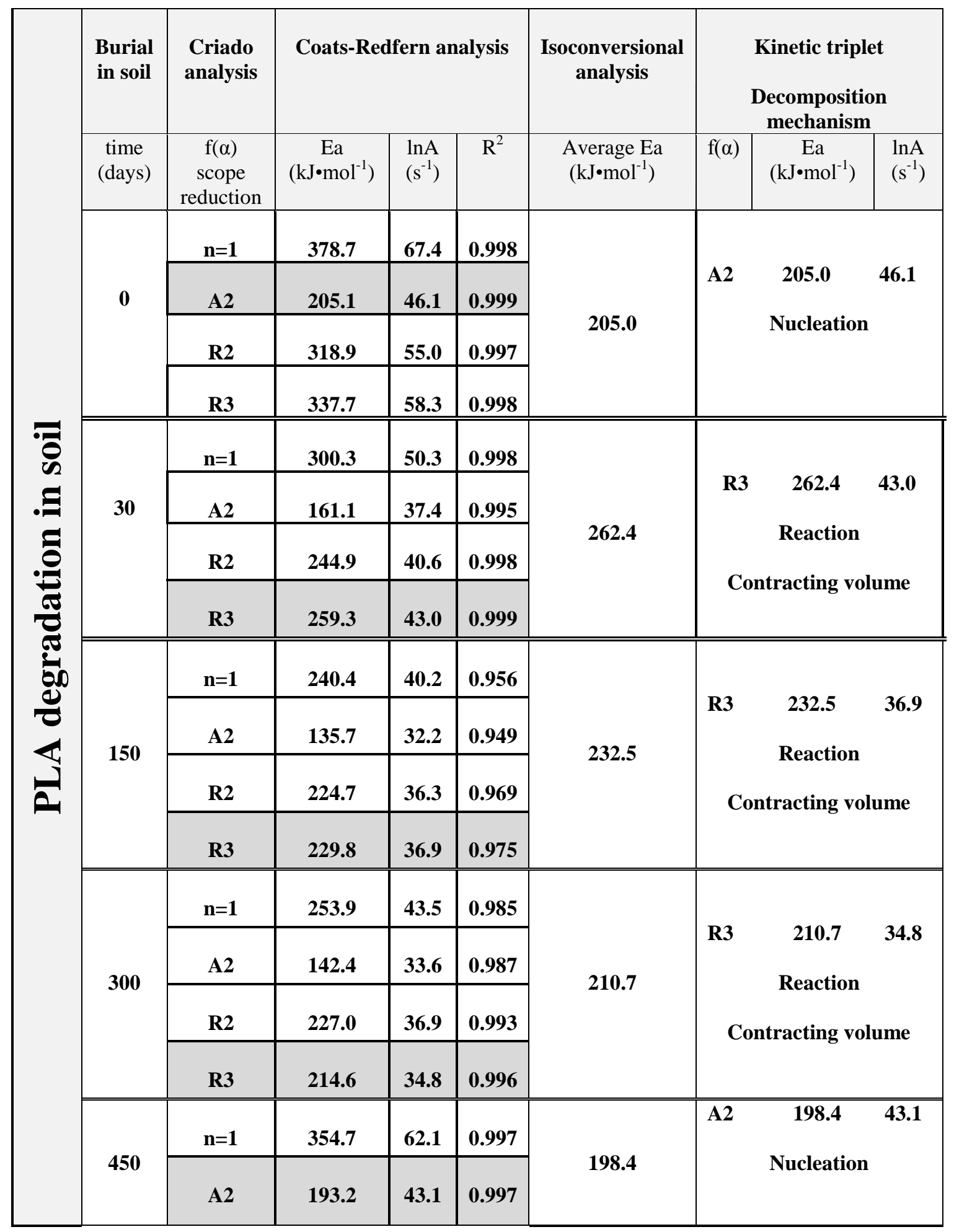


Click here to download high resolution image

Thermogravimetric analysis

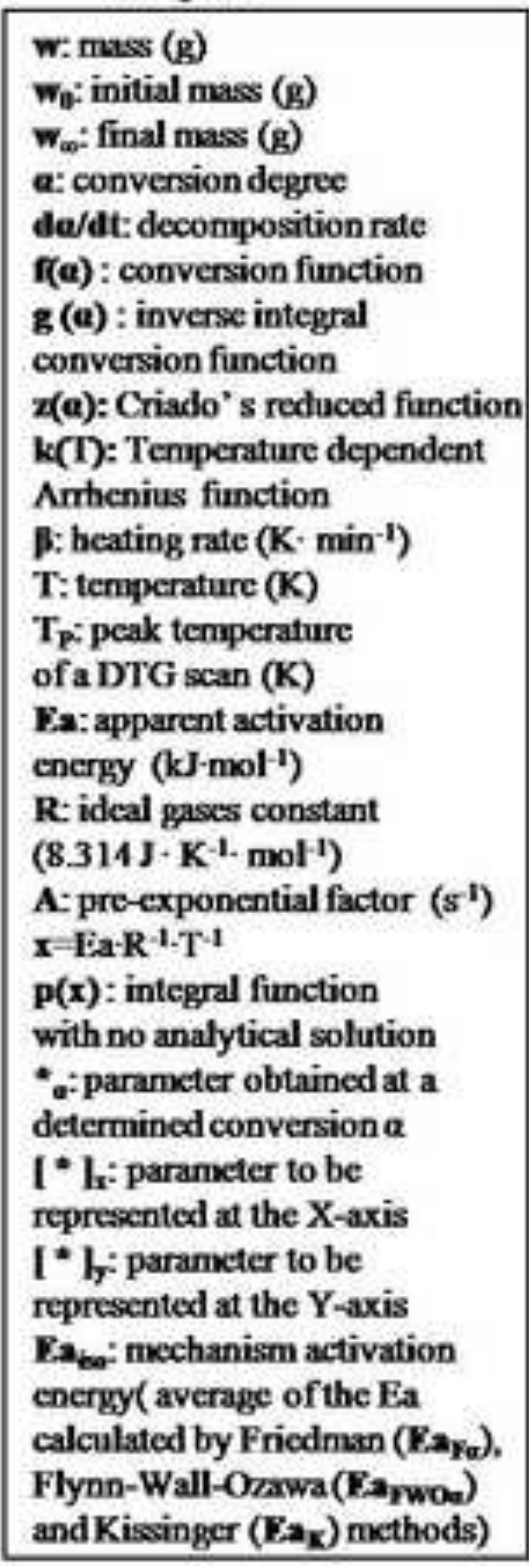

$$
\begin{aligned}
\boldsymbol{\alpha}=\frac{\mathbf{w}_{0}-\mathbf{w}}{\mathbf{w}_{0}-\mathbf{w}_{\omega}} \rightarrow \frac{\mathrm{d} \boldsymbol{\alpha}}{\mathrm{dt}}= & f(\alpha) \cdot k(T) \\
& \downarrow k(T)=A \cdot \exp \left(\frac{-E a}{R \cdot T}\right)
\end{aligned}
$$$$
\square \frac{\mathrm{d} \alpha}{\mathrm{dt}}=f(\alpha) \cdot A \cdot \exp \left(\frac{-B a}{R \cdot T}\right)
$$

Friedman

$$
\left[\ln \left(\frac{\mathrm{d} a}{\mathrm{dt}}\right)_{\alpha}\right]_{y}=\ln \left(f(\alpha) \cdot A_{u}\right)-\frac{E a_{\alpha}}{R} \cdot\left[\frac{1}{T_{\alpha}}\right]_{y} \longrightarrow E a_{F_{\alpha}}
$$

\section{Fynn-Wall-Ozawa}

$$
\frac{d \alpha}{d t}=\frac{d \alpha}{d T} \cdot \frac{d T}{d t}=\frac{d \alpha}{d T} \cdot \beta \longrightarrow g(\alpha)=\int_{0}^{\alpha} \frac{d \alpha}{f(\alpha)}=\frac{\mathrm{A} \cdot \mathrm{Ea}}{\beta \cdot \mathrm{R}} \cdot \mathrm{p}(x)
$$

Doyle's approximation $\downarrow$

$\left[\log (\beta)_{\alpha}\right]_{y}=\log \left(\frac{A_{\alpha} \cdot E a_{\alpha}}{\mathrm{R} \cdot g(\alpha)}\right)-2.315-\frac{0.457 \cdot E a_{\alpha}}{R} \cdot\left[\frac{1}{T_{\alpha}}\right]_{x}$

$$
\begin{aligned}
& \text { Kissinger }\left.\frac{d^{2} \alpha}{d t^{2}}\right|_{f_{1}}=0 \longrightarrow \\
& {\left[\ln \left(\frac{\rho}{T_{p}}\right)\right],=\ln \left(-\frac{f^{\prime}(\alpha) \cdot A \cdot R}{E a}\right)-\frac{E a}{R} \cdot\left[\frac{1}{T_{p}}\right], \rightarrow E a_{F W O_{\alpha}}}
\end{aligned}
$$

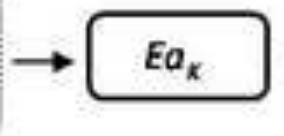

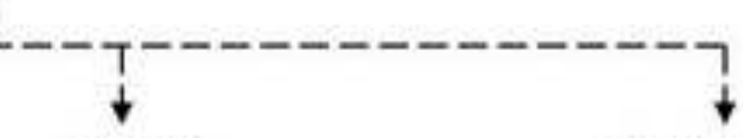

\section{Criado}

\section{Coats-Redfern}

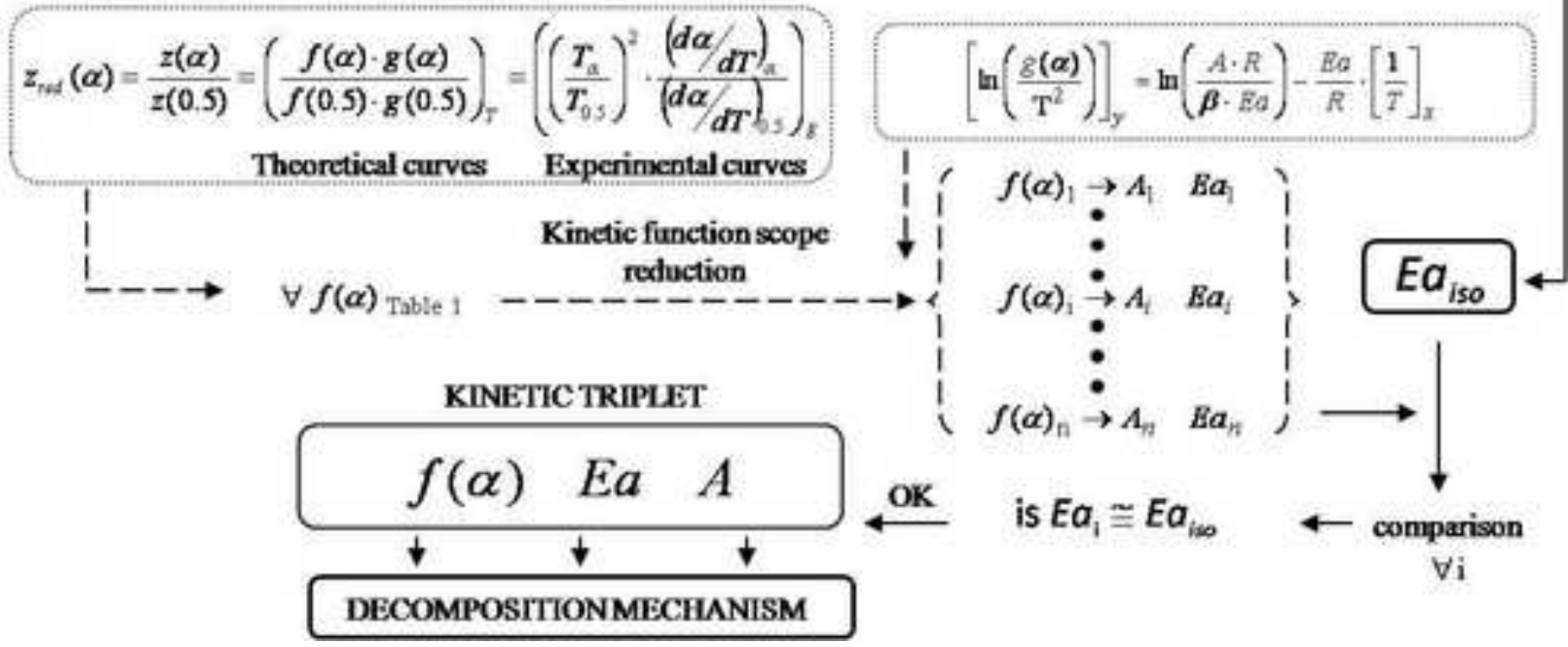




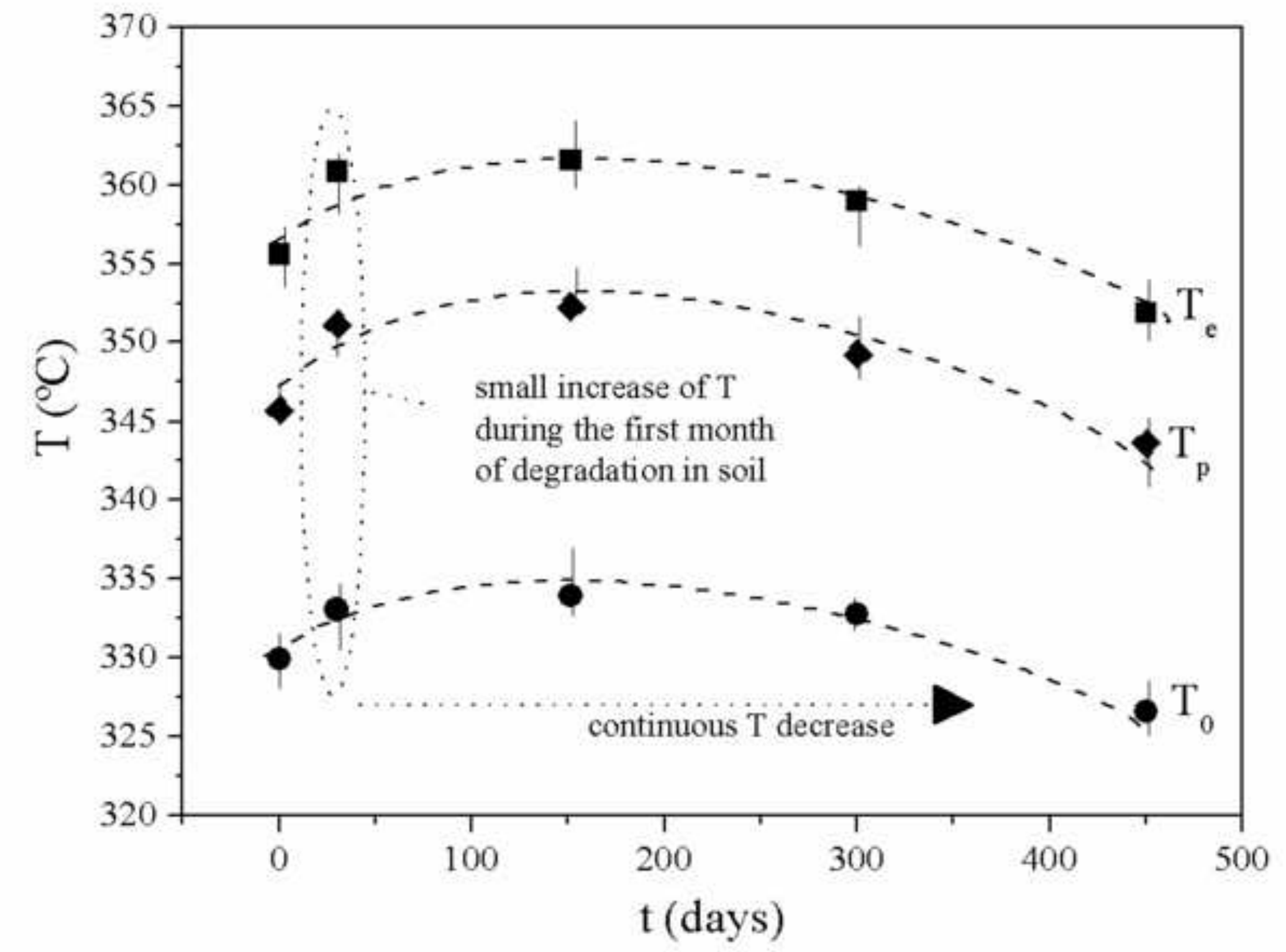

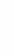




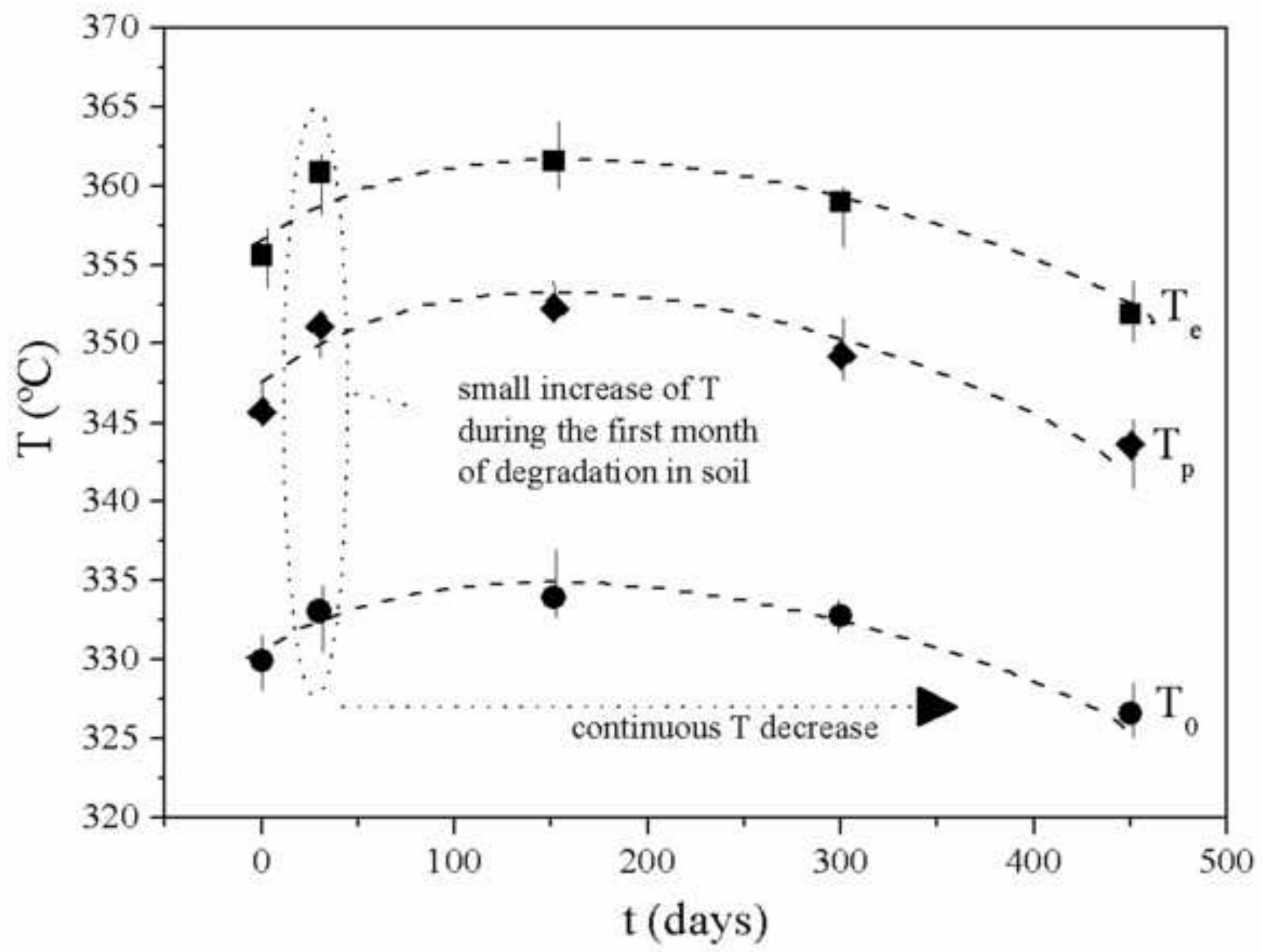


Click here to download high resolution image

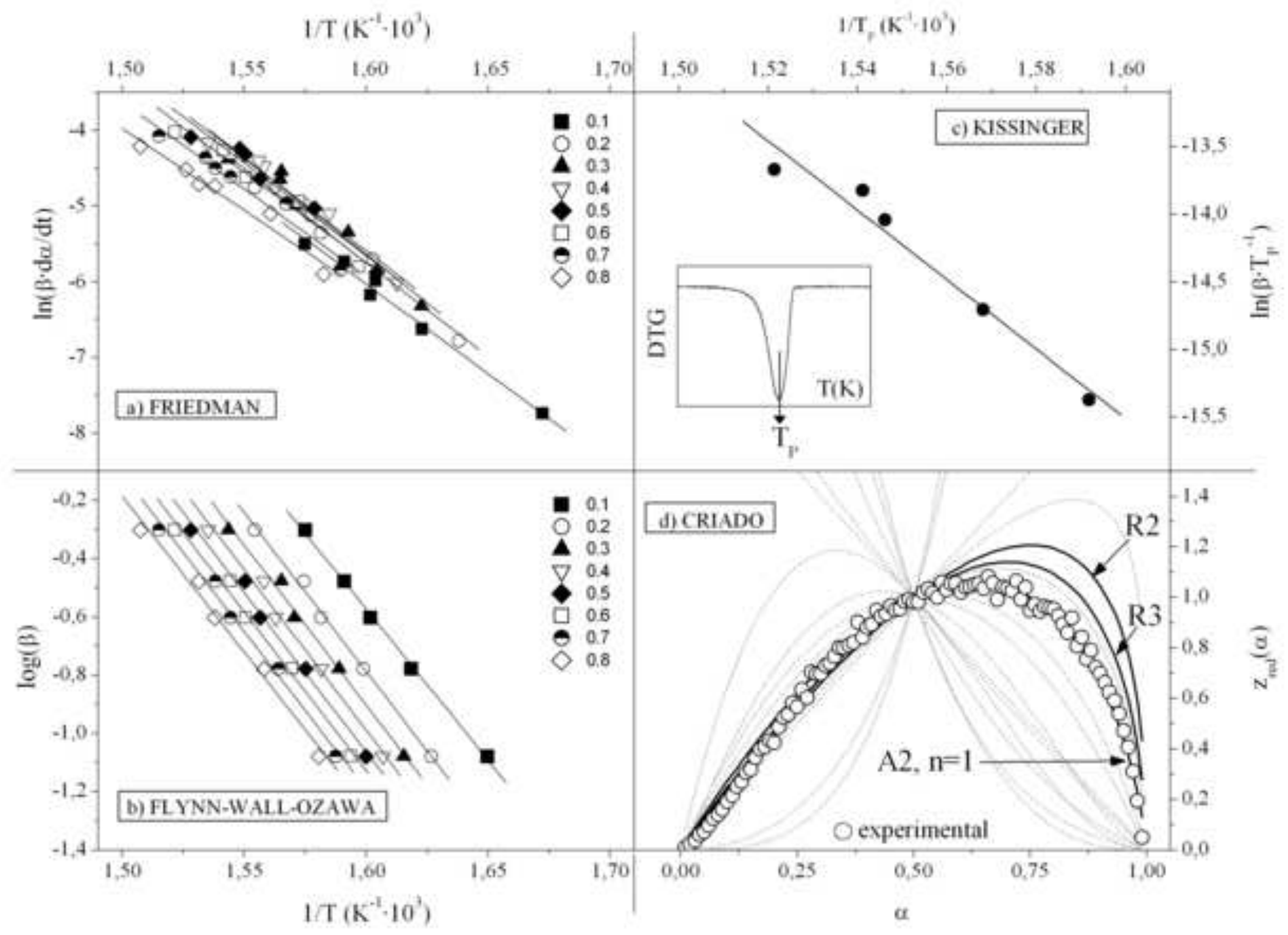




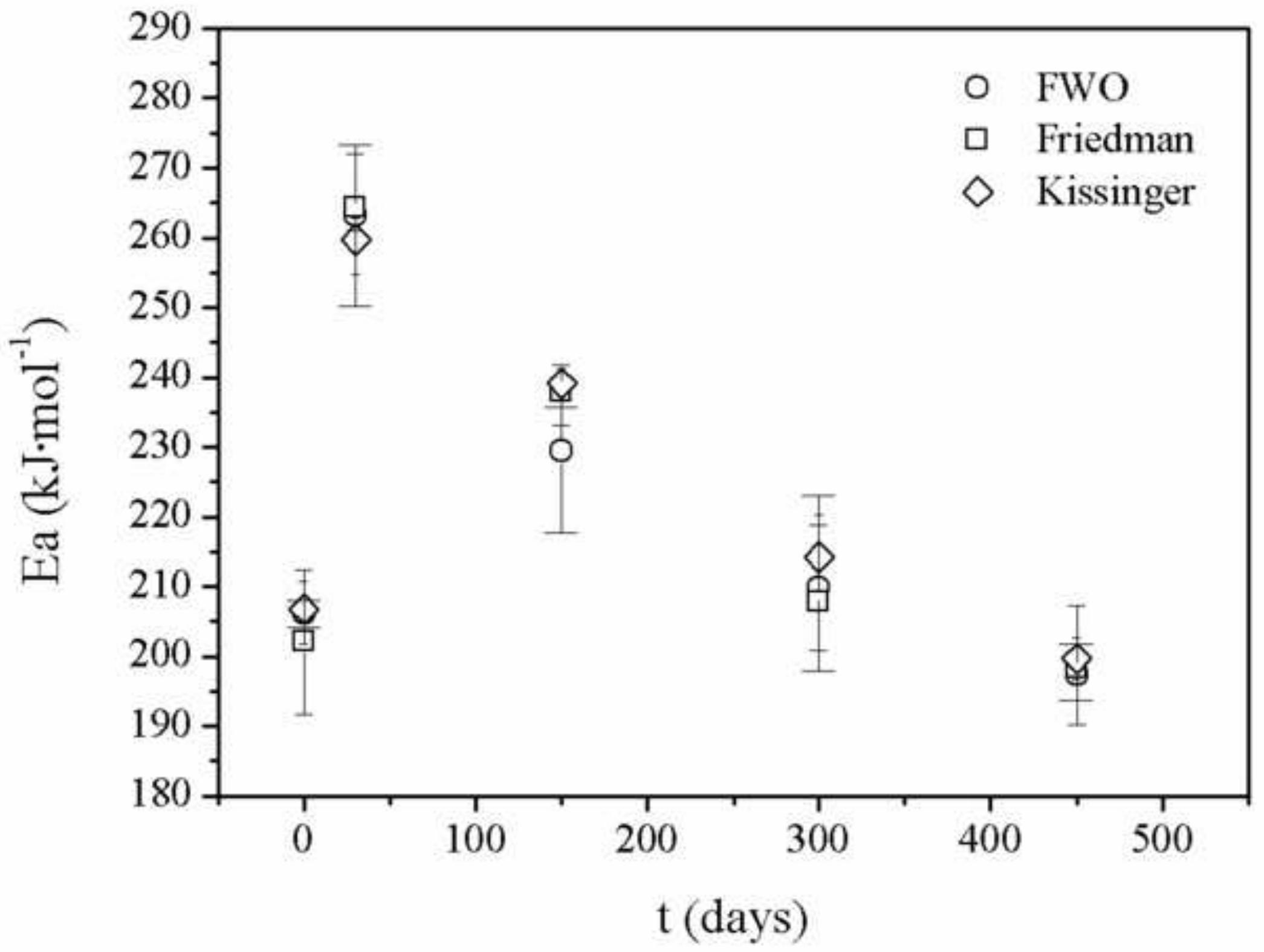




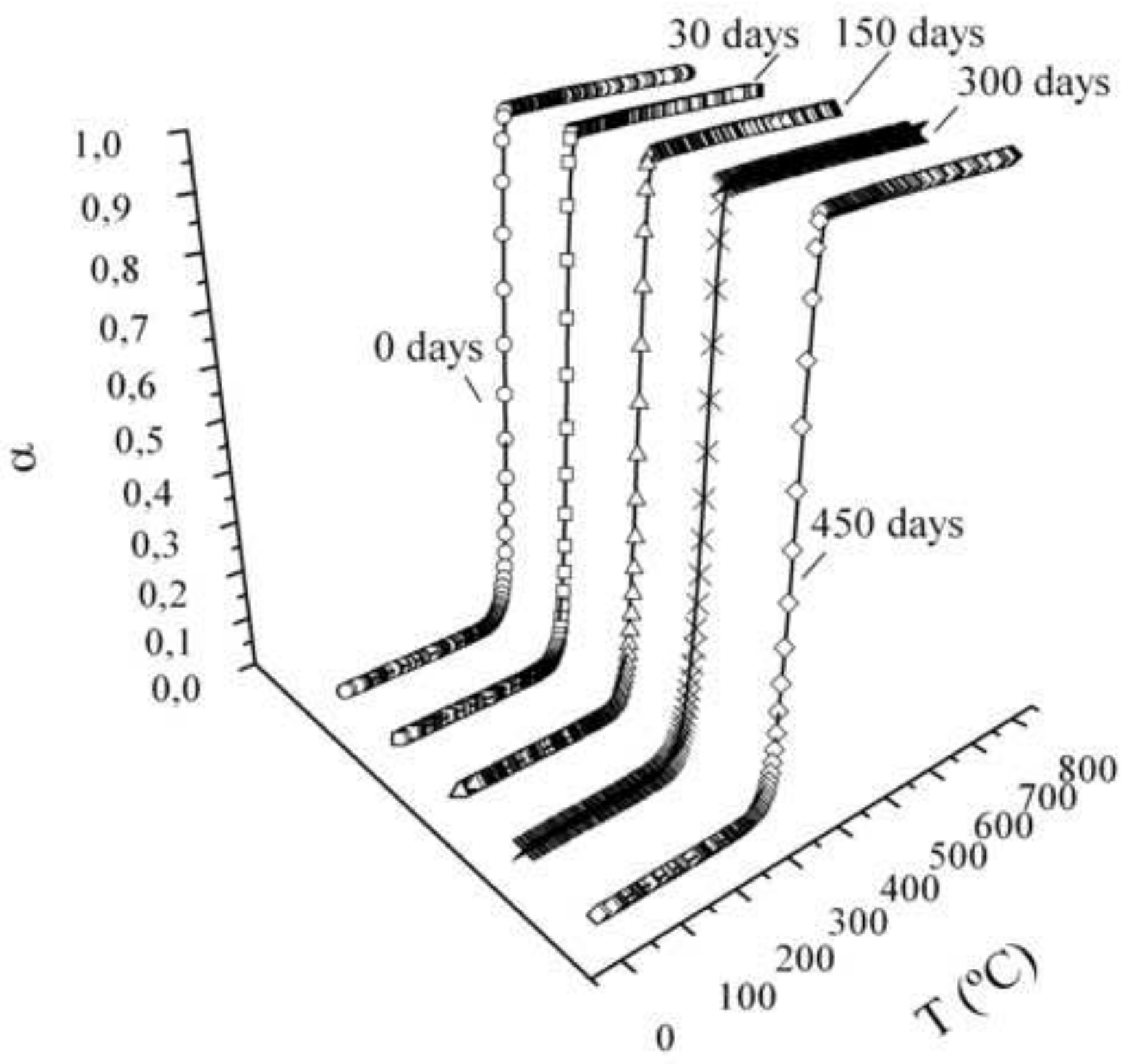


Thermogravimetric $\rightarrow \mathrm{w} \rightarrow \alpha=\frac{\mathrm{w}_{0}-\mathrm{w}}{\mathrm{w}_{0}-\mathrm{w}_{\infty}} \rightarrow \frac{\mathrm{d} \alpha}{\mathrm{dt}}=f(\alpha) \cdot k(T)$ analysis

w: mass (g)

$\mathbf{w}_{\mathbf{0}}$ : initial mass $(\mathrm{g})$

$\mathbf{w}_{\infty}$ : final mass $(\mathrm{g})$

$\boldsymbol{\alpha}$ : conversion degree

$\mathbf{d} \boldsymbol{\alpha} / \mathbf{d t}$ : decomposition rate

$\mathbf{f}(\boldsymbol{\alpha})$ : conversion function

$\mathbf{g}(\boldsymbol{\alpha})$ : inverse integral

conversion function

$\mathbf{z}(\boldsymbol{\alpha})$ : Criado's reduced function

$\mathbf{k}(\mathbf{T})$ : Temperature dependent

Arrhenius function

$\boldsymbol{\beta}$ : heating rate $\left(\mathrm{K} \cdot \mathrm{min}^{-1}\right)$

T: temperature $(\mathrm{K})$

$\mathbf{T}_{\mathbf{p}}$ : peak temperature

of a DTG scan (K)

Ea: apparent activation

energy $\left(\mathrm{kJ} \cdot \mathrm{mol}^{-1}\right)$

$\mathbf{R}$ : ideal gases constant

$\left(8.314 \mathrm{~J} \cdot \mathrm{K}^{-1} \cdot \mathrm{mol}^{-1}\right)$

A: pre-exponential factor $\left(\mathrm{s}^{-1}\right)$

$\mathbf{x}=\mathrm{Ea} \cdot \mathrm{R}^{-1} \cdot \mathrm{T}^{-1}$

$\mathbf{p}(\mathbf{x})$ : integral function

with no analytical solution

${ }^{*}$ : : parameter obtained at a determined conversion $\alpha$

$\left[{ }^{*}\right]_{X}$ : parameter to be represented at the $\mathrm{X}$-axis

[ * $]_{y}$ : parameter to be represented at the $\mathrm{Y}$-axis

$\mathbf{E a}_{\text {iso }}$ : mechanism activation energy( average of the $\mathrm{Ea}$ calculated by Friedman $\left(\mathbf{E a}_{\mathbf{F a}}\right)$, Flynn-Wall-Ozawa ( $\mathbf{E a}_{\text {Fwoa }}$ ) and Kissinger $\left(\mathbf{E a}_{\mathbf{K}}\right)$ methods)

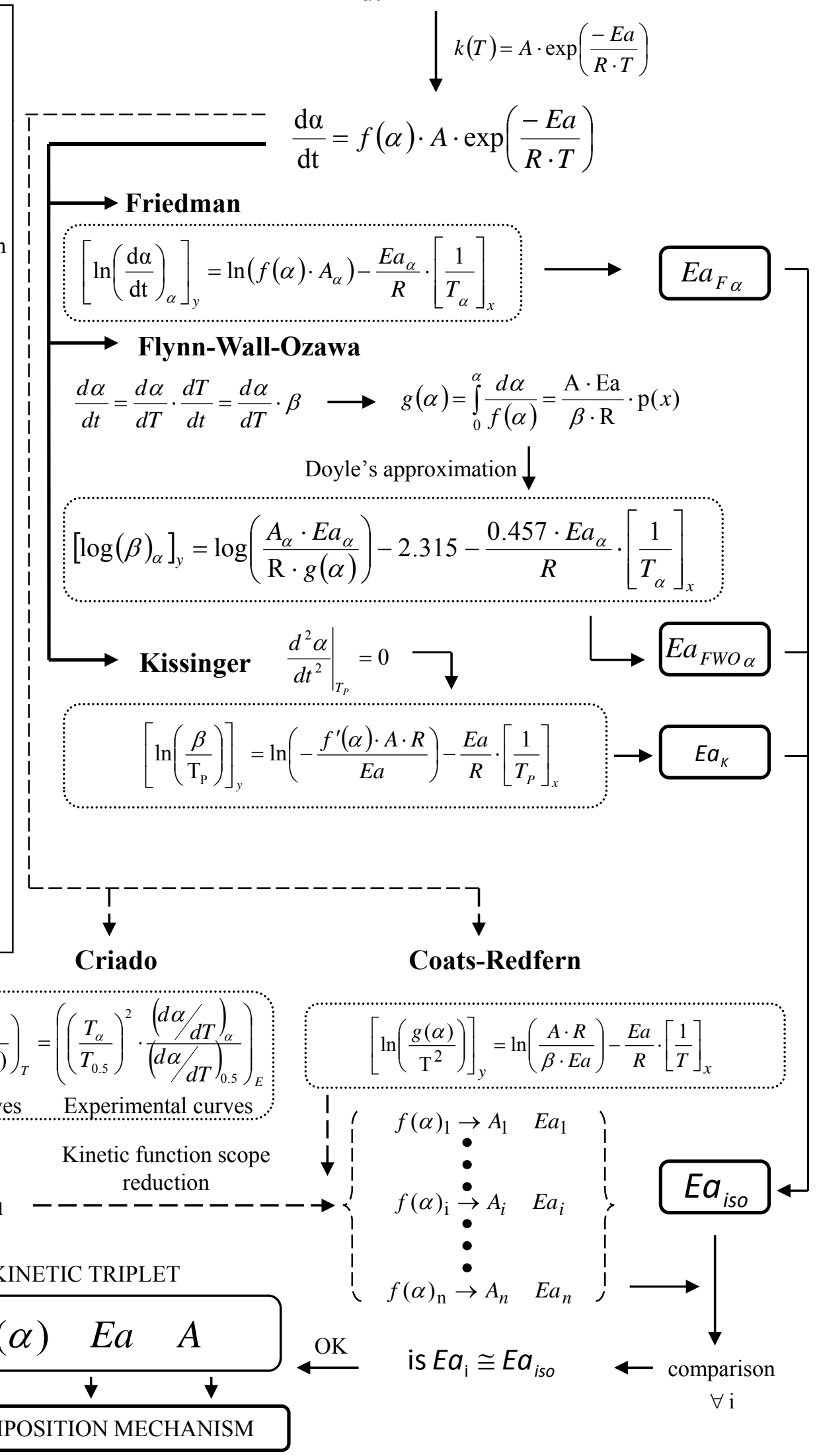

